\title{
JUVENTUDE: ETAPA DA VIDA OU ESTILO DE VIDA?
} YOUTHFULNESS: A STAGE OF LIFE OR A WAY OF LIFE?

\author{
Ana Maria Szapiro e Camila Miranda de Amorim Resende \\ Universidade Federal do Rio de Janeiro, Rio de Janeiro, Brasil
}

\section{RESUMO}

Este artigo propõe uma reflexão sobre o ideal de juventude no mundo atual a partir da emergência da nova forma-sujeito na contemporaneidade: o sujeito "causa de si mesmo", marcado pela maximização dos valores de autonomia e de liberdade. Essa forma-sujeito se constitui na ausência de um enunciador coletivo, revelando, aparentemente, uma condição de autossuficiência que, entretanto, oculta um estado de desproteção e de desamparo. Nesse cenário, esse novo sujeito acredita ser naturalmente voltado a viver livre de determinações, aberto a todas as direções e sempre disposto a recomeçar. Diante da imposição social de múltiplas performances e de flexibilidade, características da contemporaneidade, alcançar a maturidade deixou de ser um ideal a atingir, e permanecer jovem tornou-se a fórmula que melhor corresponde a essa capacidade de constante reinvenção de si. Nessa perspectiva, no mundo atual onde se deve tudo experimentar sem se fixar, ser jovem tornou-se um estilo de vida.

Palavras-chave: juventude; pós-modernidade; transmissão; estilo de vida.

\begin{abstract}
This article proposes a reflection on the youth ideal in the present world from the emergence of the new subjectform in the contemporaneity: "cause of itself", marked by the maximization of the autonomy and freedom values. This subject-form makes itself without a collective enunciator, what point to an apparent self-sufficient condition. However, this new subject also hides a state of helplessness and abandonment. In this context, the new subject believes to be free from determinations, open to all ways and always willing to start over. Faced with the social imposition of multiple performances and flexibility, characteristics of contemporaneity, reaching maturity is no longer an ideal to attain, and remain young became the way that best answers to the constant capacity to reinvention of itself. Thus, in the current world in which everything can be tried at the same time as nothing should be permanent, being young has become a lifestyle.
\end{abstract}

Keywords: youthfulness; post-modernity; transmission; way of life.

\section{A atualidade da juventude numa sociedade de indivíduos}

Marcada por inúmeras transformações, a juventude vem assumindo hoje um sentido bastante diverso do que assim se compreendia há apenas algumas décadas atrás. Os jovens pertencem a um mundo cujo valor maior e mais fundamental é hoje o valor da liberdade. Este artigo propõe uma discussão sobre o lugar da juventude na sociedade contemporânea, tomando como referência as mudanças subjetivas em curso principalmente a partir das últimas três décadas do século XX, mudanças que caracterizamos como o surgimento de uma pós-modernidade (Lyotard, 1979).

Na sua análise sobre o que acontece nos dias atuais nas nossas sociedades ocidentais nesta era pós-industrial, Lyotard (1979) chama a atenção para modificações substantivas quanto ao estatuto do saber e quanto à natureza da ciência. Há, hoje, diagnostica Lyotard (1979), uma crise dos conceitos fundamentais à modernidade, tais como o de sujeito, de razão, de verdade e de progresso.

Vivemos uma nova era que se caracteriza pelo domínio de um pensamento liberal e pela consolidação de uma sociedade de mercado. As democracias contemporâneas vivem um grande esfacelamento das instituições coletivas, que acompanhou o acento inédito, nessas sociedades, dos valores individualistas. Esse acento inédito teve como consequência a evicção mesma do sujeito moderno. A démarche moderna, invertendo a lógica antiga em que as razões do indivíduo deviam se submeter aos interesses coletivos, produziu um fenômeno novo na história da civilização ocidental: uma sociedade de indivíduos (Elias, 1991). 
O surgimento de um novo sujeito, pós-moderno (Dufour, 2005), constituiu-se em conformidade com os princípios do pensamento liberal que, a partir da segunda metade do século XX, passaram a dominar as relações econômicas das sociedades ocidentais, e também a economia das subjetividades. De certa forma, podemos dizer que o sujeito pós-moderno se constitui na transposição do modelo liberal vitorioso até então na economia. A crença de autorregulação do mercado produziu crença similar nas subjetividades: haveria nos sujeitos uma faculdade de autorregulação, prescindindo, portanto, de qualquer mecanismo de regulação coletivo. Ao sujeito, toda a liberdade, sem restrições, pois ele mesmo, como o mercado, será capaz de autorregularse, de modo a continuar a fazer sociedade. Essa lógica tem tornando as sociedades contemporâneas "doentes" de individualismo.

Szapiro (2005) ressalta que os anos sessenta e setenta, marcados por lutas contra todas as formas de repressão e de discriminação, pela igualdade de direitos entre homens e mulheres e das minorias, consolidaram a ideia de que o princípio organizador das sociedades deveria se sustentar, sobretudo, nos valores de autonomia e de liberdade dos indivíduos. Nesse sentido, a afirmação de igualdade e de liberdade de todos parece estar se sobrepondo a qualquer outro princípio, até mesmo ao real da sexuação da condição humana e da dependência inicial do pequeno ser quando chega ao mundo.

Nessa perspectiva, a generalização desses princípios de igualdade e de liberdade na experiência democrática vem produzindo uma dualidade conflituosa: de um lado, joga-se tudo pelos valores de autonomia e de igualdade dos indivíduos e, de outro lado, permanece, agora se tornando um problema, a irredutibilidade da diferença sexual e da dependência geracional. Essa dualidade conflituosa não se faz sem consequências no laço social e nas identidades, colocando, por isso, uma nova problemática no viver conjunto, no fazer sociedade.

Sabemos que é próprio do homem, por sua condição de inacabamento inaugural, por não ter uma "natureza" apta sobre a qual ele possa se apoiar e sobreviver por si mesmo, ter que construir para si uma segunda natureza, capaz de lhe permitir fazer face ao seu inacabamento (Dufour, 2005). Neóteno, eternamente às voltas com sua inaptidão e incompletude, o homem é e sempre foi, por isso mesmo, livre para criar seu próprio destino e suas ficções de origem. Essas funcionavam como princípios unificadores, se constituíam em enunciadores coletivos sobre os quais os neótenos se apoiavam. Em outras palavras: "as realidades políticosimbólicas criadas correspondem a uma necessidade psíquica. É nesta fonte profunda que se apóia a servidão voluntária do neóteno" (Dufour, 2005, p. 101) ${ }^{1}$.
O caráter histórico da constituição dos enunciadores coletivos vem sendo ressaltado na obra de Dufour (2005) quando, tomando emprestado de Lacan o termo "Outro" para distingui-lo de qualquer aspecto meramente especulativo, os denomina "Grande Outro". Esses enunciados funcionam como princípios unificadores, assumiram diferentes configurações ao longo da História de acordo com as diferentes épocas, e perduravam na medida em que suportavam sua função de fazer face ao desamparo da condição humana de inacabamento.

O homem chega ao mundo inacabado, incapaz de sobreviver sem a ajuda decisiva de um outro. É o princípio organizador que lhe oferece um ponto de apoio; a ele o sujeito se submete, tornando possível sua existência. O "Grande Outro" é esta anterioridade fundadora a partir da qual uma ordem temporal se torna possível. E é através dessa anterioridade que irá se fundar uma interioridade. Na contemporaneidade, entretanto, como bem observa Dufour (2004) em $A$ arte de reduzir as cabeças, não temos mais nenhuma figura capaz de ocupar este lugar de prestígio inconteste representado pelo "Grande Outro", pois que o próprio da pós-modernidade é exatamente a recusa a qualquer figura de exceção simbólica necessária ao processo de constituição desse lugar do "Grande Outro".

Sem referências nas quais se possa fundamentar uma anterioridade e uma exterioridade simbólicas, o sujeito não consegue se manifestar numa espacialidade e numa temporalidade bastante amplas. Deixa-se iludir por um presente onde se joga tudo. A relação com os outros se torna problemática, na medida em que tudo é jogado num instante, então o projeto, a antecipação, o retorno sobre si próprio tornam-se operações altamente problemáticas. (Dufour, 2001, p. 6)

\section{Vicissitudes do "ser jovem" nos dias atuais...}

A condição subjetiva desse novo sujeito da pósmodernidade, como dissemos, tem importantes consequências nas identidades e no projeto de sociedade. Vamos tratar aqui de uma dessas consequências, qual seja, das mudanças em curso relacionadas ao que denominaremos, de um modo muito geral, de "etapas da vida", ou "idades da vida", expressões que tomamos de Marcel Gauchet (2004).

A ideia de juventude hoje apresenta características muito particulares, que podemos associar à condição pós-moderna. Assim é que para muitos jovens, marcados pelo pensamento liberal, o presente é o que importa. O futuro vai sendo tecido dia após dia, sem grandes planos ou objetivos de longo prazo de vida. Como indivíduos autônomos e livres, suas ações parecem ser determinadas apenas tendo como objetivo maior 
a maximização de um estado de prazer. $\mathrm{O}$ desprazer passou a ser percebido como uma circunstância a ser eliminada, pois que não deveria fazer parte da vida. Poderíamos argumentar que isso foi sempre assim. Entretanto, algumas diferenças importantes precisam ser consideradas, pois marcam as mudanças nos processos subjetivos em marcha.

$\mathrm{Na}$ modernidade, neste "não lugar" próprio da adolescência - como se denominava aquele período da vida entre a infância e a idade adulta -, distinguia-se uma inclinação à adesão ao ideal de uma vida de prazeres, restando, entretanto, sempre, a aceitação da impossibilidade de evitarem-se, na realidade, as experiências de desprazer. No mundo atual, o ideal almejado de um estado de permanente prazer parece, para o jovem, ter se tornado algo perfeitamente possível de ser alcançado. Algo da ordem de um imperativo que impulsiona o sujeito a acreditar que a realidade do desprazer deve e pode desaparecer da experiência do viver.

Hoje, os jovens se veem autônomos num mundo destradicionalizado ou em processo de acelerada destradicionalização, se considerarmos que o último lócus de relações hierárquicas - a família - vem passando, nas últimas décadas, por transformações enormes em que as figuras parentais deixam, lentamente, de exercer sua função de autoridade legitimada pela diferença geracional. Assim, muito mais do que autônomos, os jovens hoje se sentem livres para decidirem sobre suas vidas.

$\mathrm{Na}$ verdade, eles se encontram, paradoxalmente, numa situação simbólica de abandono e se tornam, assim, presas fáceis de um aparelho poderoso regido pela lógica da sociedade de mercado, que não cessa de lhes oferecer "mais prazer" através de mais objetos a consumir, sugerindo-lhes que consumir é exercer o direito de escolher. A cada momento um objeto, a cada momento um novo prazer, ao qual se sucede uma nova busca por mais prazer.

Esta produção de sujeitos instáveis, insaciáveis, eternamente em busca de prazer, está em perfeita consonância com o mundo do novo capitalismo de mercado. Essa nova forma de capitalismo age através de mecanismos muito sutis, bem menos constrangedores que aqueles da modernidade, da sociedade disciplinar analisada por Foucault (1984) em Vigiar e Punir. Esses novos mecanismos não são nem punitivos nem onerosos no ofício de se garantirem. Trata-se de capturar desejos, transformando-os em necessidade de consumir objetos. Hoje não se trata mais de opor-se às instituições - opor-se à escola, aos pais, à direção, à autoridade, enfim - para tentar questioná-las, como nos discursos críticos dos anos sessenta e setenta. Trata-se de esvaziar o lugar mesmo da autoridade, da direção, da diferença. A horizontalidade em todas as relações elimina os obstáculos, eliminando assim tudo aquilo que poderia servir de entrave à livre circulação do mundo das mercadorias. Não há que governar, apenas gerir, pois que, numa sociedade de iguais, cabe apenas a gestão das relações.

Esse esfacelamento, que na verdade constituiu um movimento de desinstitucionalização, atua retirando a legitimidade do instituído. É nessa perspectiva que concordamos com Dufour (2004) quando se refere aos efeitos sobre o sujeito dessa desinstitucionalização generalizada - da família, da escola, do Estado enquanto governo - como um processo de dessimbolização. Nessa medida, tudo aquilo que se refere a princípios e a ideais e que não é conversível em mercadoria é descartado, esvaziado de sentido. Assim, os interditos que, como tais, fazem sociedade por serem a lei, perdem legitimidade, não constrangem mais o sujeito que, à deriva, busca apoio no mundo das mercadorias vestidas como verdadeiras próteses identitárias.

É possível que nos encontremos, nesse sentido, diante de uma situação de anomia social com efeitos graves para o viver em sociedade. No estado de anomia, termo criado por Durkheim (1897/2000) para descrever uma sociedade sem regras claras, os valores ligados à história da sociedade e da cultura desaparecem, perdem o valor, deixam simplesmente de ser considerados, até mesmo para serem experimentados e poderem ser negados. Uma sociedade que não examina suas tradições não pode nem mesmo se opor a elas. Nessa situação, a transmissão geracional tende a se inverter: são agora os mais jovens que devem transmitir os valores do mundo atual aos mais velhos para que esses possam viver, nesse sentido, "dentro" do tempo.

Os lugares simbólicos que marcam a passagem da juventude à idade adulta estão em franco processo de desaparecimento. Sem que se possa constituir uma relação de transmissão adulto-jovem, o jovem parece ter que se autoconstituir simbolicamente. O lugar da alteridade, da diferença na sua radicalidade, a partir do qual é possível nos constituirmos como sujeitos na nossa singularidade está, assim, comprometido.

Como consequência, assistimos ao surgimento de novas formas de violência na juventude que, a nosso ver, estão relacionadas a esse esfacelamento das instituições a que nos referimos acima e aos problemas de legitimidade na transmissão geracional. Exemplos dessas novas formas de violência são hoje fartos na mídia nacional e internacional. Surgem como resultado da ausência de um ponto de ancoragem em um "Grande Outro".

Os processos de dessimbolização aparecem claramente nas justificativas dadas para atos de violência cometidos. A impossibilidade de atribuição de sentido 
e de relação entre os atos e suas intenções aponta para derivas onipotentes construídas como tentativas de remediar um estado de abandono simbólico, pela ausência de qualquer ponto de ancoragem.

A onipotência é o reverso do desamparo. $\mathrm{O}$ ato de violência funciona aqui como uma resposta a esse desamparo, em que o sujeito tenta assumir, ele mesmo, o lugar desse "Grande Outro", numa espécie de autoconstituição que faça face ao desamparo. Não há, no discurso dos autores dos atos de violência, a referência a um sentimento de culpa, o outro parece ter sido um mero objeto. Nos discursos, transparece a crença de que os autores da violência se outorgaram o poder de vida ou de morte, investindo-se, a si mesmos, de um poder soberano. Não há, de modo geral, menção à ideia do que é ou não é permitido socialmente fazer.

Identificamos, com Wieviorka (1998), nas justificativas para tais atos de violência, uma mudança de paradigma. Esse autor denomina essa mudança paradigmática de "privatização da violência", consequência dos processos de desinstitucionalização, em que o espaço da experiência pública foi esvaziado, desapareceu, e a vida social passou a ser totalmente tomada pela lógica das razões da vida privada, pelas razões de cada um, individualmente. Não se trata aqui de efeito de individualismo, mas sim de efeito de excesso de individualismo, como se o sujeito estivesse sofrendo desse excesso por total ausência de referências que o permitam localizar-se no dentro ou no fora da regra de sociabilidade por ele jamais experimentada.

Esse novo sujeito desamparado é, portanto, também vítima. Os jovens que hoje queimam, saqueiam e agridem, justificando seus atos com uma aparente gratuidade de razões, nos revelam esse estado subjetivo de impotência decorrente da ausência da transmissão de referências que falávamos acima. A experiência da transmissão, por implicar a submissão a valores já constituídos e não escolhidos pelo livre arbítrio, é o que poderia permitir aos jovens confrontarem-se com suas fragilidades e com os limites que são impostos pela vida em sociedade - limites que foram notavelmente expostos por Freud em "O mal-estar na civilização" (Freud, 1929/1974). Está na experiência de transmissão intergeracional o ponto de partida para a constituição de novos valores das novas gerações.

O que importa aqui sublinhar é que a experiência de submissão que oferece a transmissão geracional é o que torna possível a simbolização, a tomada de posição, a aceitação, a negação, a construção do novo, a crítica ao antigo, enfim, a compreensão de que a condição humana é a de ter limites e de que esses limites não se constroem segundo o livre-arbítrio de cada um. As singularidades se constituem nos e a partir dos interditos.
Num mundo que pretende se livrar das tradições, pouco parece ter restado aos pais dos jovens que se encontram nesta condição de autoconstituição. Nessa subjetividade, a função paterna de interdição se tornou difícil de sustentar, já que vivemos numa época em que ser jovem, ao contrário de representar uma condição subjetiva de um tempo de transição e de aprendizado para a entrada no mundo dos adultos, tornou-se a condição ideal a que todos devemos almejar e conquistar permanentemente. A condição de jovem é a permissão para o livre exercitar de todas as experiências, sem restrições.

Aliada a esse discurso que afirma como ideal para toda a sociedade uma nova condição de existir, que é a de ser jovem, surge um novo imperativo: aos pais, antes da tarefa de educar, parece se impor um novo objetivo - a conquista do amor dos filhos. Nesse sentido, relegada a tarefa de educar a um lugar secundário, ou até mesmo negada, faz supor que hoje os pais parecem acreditar que o "pequeno ser" que acaba de chegar ao mundo já é um sujeito, tendo incorporado os códigos da cultura e os modos de lidar com estes. Parece que ser sujeito passou a ser visto hoje não como sendo uma construção, não como um processo que passaria por uma alteridade que resiste e que, negando o pleito ao gozo sem limites, educa.

Esse novo imperativo de conquista do amor dos filhos, segundo bem analisa Lebrun (2007), faz com que o papel de educar os filhos seja hoje interpretado pelos pais como um papel ingrato, perigoso, pois pode levá-los à perda do amor dos filhos, razão pela qual os pais temem cumpri-lo. Daí a ideia hoje comumente partilhada de que os pais são tanto melhores quanto mais sejam bons "amigos" dos seus filhos. Como observa ainda Lebrun (2007), se na subjetividade moderna os filhos se colocavam como questão a conquista do amor dos pais, hoje são os pais que procuram ser amados pelos filhos. Nesse sentido, na medida em que a demanda de amor dos pais faz obstáculo ao projeto de educar, de transmitir códigos e valores que constituem a sociedade, devemos nos perguntar: o que chamamos hoje de educação?

\section{Que transmissão é hoje possível?}

Como consequência dessas transformações, os mecanismos de transmissão em que se fundam as relações no interior das famílias também se modificam. O que ocorre atualmente é, sobretudo, uma mudança de função da família como instituição responsável pela reprodução social. Disso advém o desconhecimento e a desvalorização de toda a experiência de transmissão intersubjetiva. Há um estranhamento, no sentido de um alheamento, por 
parte dos mais jovens sobre um saber que as gerações anteriores teriam a transmitir (Szapiro, 2003).

Moisseeff (1992), no mesmo sentido crítico de Szapiro (2003), argumenta que hoje se instaura uma perspectiva genética na transmissão. Segundo Moisseeff (1992), essa perspectiva genética tomou o lugar da genealógica. Esta última pressupunha a transmissão da identidade social e familiar de uma geração para outra. Havia, portanto, uma incontestável preparação das gerações mais novas pelas gerações anteriores. Hoje, se há transmissão, o que sobressai são os fatores biológicos, e não a transmissão de uma identidade social e familiar. Assim, segundo Szapiro (2003), os laços geracionais se transformaram, o que podemos notar pela ausência, na atualidade, dos enfrentamentos necessários - porque constitutivos - no processo de transmissão geracional.

Hoje não se observam os grandes conflitos que marcam a passagem de uma geração à outra. Essa passagem só se faz através de um trabalho psíquico que passa por uma necessária idealização dos pais tomados como referência e como modelo. Num momento posterior, através de um trabalho de desidentificação, seria possível ao sujeito se constituir na sua alteridade, mas não sem antes ter passado pelas vicissitudes das experiências do confronto intergeracional. Esse confronto se traduz no esforço psíquico das novas gerações para "provar" à geração anterior que agora podem participar do mundo adulto, trazendo, de alguma forma, seus novos olhares sobre o mundo.

São inúmeras as dimensões atualmente esvaziadas do sentido de confronto que nos indicam o quanto foi retirado dos adultos/pais o lugar de autoridade que resultava da função de transmissão que por eles passava. No mundo atual, a idade adulta deixou de ser uma fase valorizada pelo reconhecimento de uma experiência que deve ser considerada legítima pelos mais jovens. É esse o centro do argumento de Gauchet (2004), quando afirma que estamos testemunhando a desagregação do que se chamava de maturidade e a liquidação do que se compreendia como "idade adulta". Os pais passaram a ser "os velhos de um mundo ultrapassado". A vida dos pais, vista pelos mais jovens como carregada de limitações, traz um significado esvaziado de valor.

\section{A juventude como ideal de existência}

Ao contrário de quando a fase adulta era um modelo desejado, hoje se manter jovem transformou-se em um ideal de existência (Gauchet, 2004; Bozon, 2004). Manter-se jovem é essencialmente não se fixar, não se alienar no já realizado que já é, de imediato, passado. Manter-se jovem demanda a construção de um "eu" de caráter provisório, como assinalamos. O ideal é ser o menos adulto possível, explorar as vantagens e evitar inconvenientes, mudar de emprego com frequência e sem dificuldades, manter relacionamentos amorosos apenas enquanto ambos os parceiros acharem que estão felizes. O ideal é explorar permanentemente - e isso em qualquer idade - o que Gauchet (2004) chama de "liberdade de construir", que sempre foi atribuída apenas à juventude por esta representar o início de toda uma vida a ser construída.

Hoje, a "liberdade de construir" tornou-se um imperativo generalizado e permanente para todos. Com os avanços no âmbito das tecnociências, em especial no campo da biogenética, tudo parece se tornar possível através das soluções encontradas nessas tecnologias. Um exemplo disso é a possibilidade que a ciência oferece à mulher de ser mãe inclusive numa idade avançada, quando o processo de envelhecimento dos órgãos reprodutores tendo decretado sua obsolescência já não mais permitiria a realização desse desejo. Assim sendo, todos estamos jovens, como modo de existir.

A atitude diante do envelhecer é a de que é possível vencer o envelhecimento, mantendo-se jovem até morrer, morrer jovem! Para tal, não só os desenvolvimentos atuais nas tecnociências são, nesse sentido, bastante promissores, como o mercado oferece a possibilidade de comprarmos um estilo de vida "jovem". Um exemplo disso é o vestuário: só há um estilo de moda - bebês, crianças, jovens, adultos ou idosos, todos devem vestir-se como jovens.

A idade adulta não só não mais se apresenta como um lugar que se ambiciona ocupar como, ao contrário, pode significar um mal-estar: a saída, a perda da juventude. Para evitar esse mal-estar impõe-se, então, ao sujeito, um esforço de negação de seu próprio percurso, este que o localiza num tempo, na sua história. É preciso reinventar, por todos os meios, um novo percurso, produzindo-se como alguém jovem, sem limitações ou restrições, inclusive aquelas relativas ao envelhecimento do corpo. Essa reinvenção, vale reafirmar, não se faz sem custos psíquicos importantes. Em resumo: a juventude deixa de ser uma etapa da vida para tornar-se um ideal a conservar (Gauchet, 2004).

Dado que a juventude não mais representa um momento de transição da infância para a idade adulta, como definia o antigo conceito de adolescência, assistimos hoje, nas sociedades ocidentais contemporâneas, a um acontecimento de expressão civilizacional (Gauchet, 2004), que é o desaparecimento da revolta e da luta juvenil. Motivos de frustração associados à dependência e à luta por ideias opostas às gerações anteriores, que tanto incitavam os comportamentos dos jovens de outrora, hoje estão desaparecendo. 
Nossas sociedades passaram a compreender a liberdade e a autonomia como propriedades intrínsecas dadas desde o início, um estado quase que natural à vida em sociedade. Identificamos nessa compreensão contemporânea da liberdade e da autonomia uma das causas desse acontecimento de expressão civilizacional assinalado por Gauchet (2004). Dessa forma, liberdade e autonomia, qualidades vistas como propriedades naturais a cada um, tendem a desaparecer enquanto objetivos de qualquer projeto de luta para os jovens de hoje (Szapiro, 2003). Porém, vale assinalar a observação de Dufour (2005) quando destaca que nada garante que a autonomia se constitua como uma exigência acessível a todos os sujeitos. Os que conseguem alcançá-la são, muitas vezes, aqueles que eram antes "alienados" e tiveram que lutar para se libertar. Os que nunca foram alienados nem por isso podem ser considerados autônomos e livres. Muito pelo contrário, esses, comumente, se apresentam mais abandonados do que livres (Dufour, 2005).

A juventude, neste mundo onde não há mais adultos, pertence hoje a um mundo de indivíduos que se acreditam já nascerem livres de todos os constrangimentos que deveriam fazer parte das conquistas necessárias para o fazer sociedade. No entanto, como dissemos, a experiência das gerações anteriores, porque se constitui no próprio patrimônio acumulado a ser transmitido às novas gerações, só pode ser verdadeiramente ultrapassada ou rompida se for transmitida. Como ainda argumenta Marcel Gauchet (debate transmitido pela Radio France Culture Transmission, dezembro de 2004): "nous sommes aujourd'hui dans une configuration assez nouvelle, dans un moment qu'on peut qualifier d'acceleration de l'histoire... dans un parachèvement de la nouveauté et de la legitimation non pas par le passé mais plutôt par l'avenir..."2

Como uma espécie de ardil da própria História, com a transformação da juventude numa espécie de virtude em si mesma e, nesse sentido, com a desvalorização do patrimônio das gerações do passado, desapareceram também os recursos subjetivos de superação - ou mesmo de subversão e de crítica - aos valores do mundo de ontem.

Posto que se faz tabula rasa da experiência passada, não é mais possível conhecer essa experiência para a ela se opor verdadeiramente. Parece que nos tornamos, assim, prisioneiros dos artifícios mercadológicos que colocam o novo e o diferente nas vitrines como mercadorias disponíveis para serem adquiridas - não conquistadas.

A juventude transformou-se em um estado que se almeja que seja eterno. Assim sendo, é possível que estejamos vivendo hoje a experiência mais historica- mente conservadora e acrítica dos valores de todos os tempos anteriores, uma vez que ser jovem, em resumo, constitui-se hoje no trabalho permanente de modular-se como um objeto de consumo numa economia de mercado que se alimenta da crença segundo a qual somos, e somos felizes, se somos o novo. Não como uma escolha, mas como um novo imperativo: a juventude. A esta busca, o capitalismo de mercado nos sugere: seja jovem e pertença a este mundo!

\section{Notas}

1 Tradução livre das autoras.

2 "Nós estamos hoje numa configuração muito nova, num momento que podemos qualificar de aceleração da história, num aperfeiçoamento da novidade, de uma legitimação não pelo passado, mas antes pelo futuro" [tradução livre das autoras].

\section{Referências}

Bozon, M. (2004). Sociologia da sexualidade. Rio de Janeiro: FGV.

Durkheim, E. (2000). O suicídio: estudo de sociologia. São Paulo: Martins Fontes. (Original publicado em 1897)

Dufour, D.-R. (2001, fèvrier). Les désarrois de l'individu-sujet. Le Monde Diplomatique, pp.16-17.

Dufour, D.-R. (2004). A arte de reduzir as cabeças: sobre a nova servidão na sociedade ultraliberal. Rio de Janeiro: Companhia de Freud.

Dufour, D.-R. (2005). On achève bien les hommes. Paris: Denoël.

Elias, N. (1991). La société des individus. Paris: Librairie Arthème Fayard.

Foucault, M. (1984). Vigiar e punir: nascimento da prisão $\left(3^{\mathrm{a}}\right.$ ed.). Petrópolis, RJ: Vozes.

Freud, S. (1974). O mal-estar na civilização. In Edição standard brasileira das obras completas de Sigmund Freud (Vol. 21, pp. 81-141). Rio de Janeiro: Imago. (Original publicado em 1929)

Gauchet, M. (2004, novembre-décembre). La redéfinition des âges de la vie. Le débat: histoire, politique, société, 132, 27-44.

Lebrun, J.-P. (2007). La perversion ordinaire: vivre ensemble sans autrui. Paris: Denoël.

Lyotard, J.-F. (1979). La condition postmoderne: rapport sur le savoir. Paris: Les Édition de Minuit.

Moisseeff, M. (1992). Enjeux anthropologiques de la thérapie familiale avec les adolescents. In C. Gammer \& M.-C. Cabié (Orgs.), L'adolescence, crise familial: thérapie familiale par phases (pp. 205-227). Paris: Érès.

Szapiro, A. (2003, $1^{\circ}$ semestre). O indivíduo fora da cidade: questões à transmissão na sociedade contemporânea. Estudos e Pesquisas em Psicologia, 1, 45-57.

Szapiro, A. (2005, $1^{\mathrm{o}}$ semestre). Em tempos de pós-modernidade: vivendo a vida saudável e sem paixões. Estudos e Pesquisas em Psicologia, 1, 25-37.

Wieviorka, M. (1998, automne-hiver). Le nouveau paradigme de la violence (partie 3). Cultures \& Conflits, 28, 44-57. 
Recebido em: 2008-12-30

Revisão em: 25/01/2010

Aceite final em: 02/02/2010

Ana Maria Szapiro é Professora do Instituto de Psicologia da UFRJ e do Programa de Pós-Graduação em Estudos Interdisciplinares de Comunidades e Ecologia Social/ Instituto de Psicologia/ UFRJ. Endereço: Rua Gustavo Sampaio 710, ap. 202.Rio de Janeiro/RJ. CEP 2210-010 Email: anaszapiro@uol.com.br
Camila Miranda de Amorim Resende é Professora do Centro Universitário São José de Itaperuna. É psicóloga e mestre em Psicossociologia de Comunidades e Ecologia Social pelo Programa EICOS de Pós-Graduação/Instituto de Psicologia/UFRJ.

Email: camila.mdamorim@gmail.com

\section{Como citar:}

Szapiro A. M. \& Resende, C. M. A. (2010). Juventude: etapa da vida ou estilo de vida? Psicologia \& Sociedade, 22(1), 43-49. 